\title{
Upper Cervical Spine Stability: Maximum Rotation and the Rotation Stress Test in Clinics
}

\author{
Ana I. Lorente ${ }^{1}$, Mario Maza Frechín ${ }^{1}$, Albert Pérez Bellmunt² ${ }^{2}$ César Hidalgo García ${ }^{3}$ \\ ${ }^{1}$ Investigación y Desarrollo en Ergonomía (IDERGO) \\ Instituto de Investigación en Ingeniería de Aragón (I3A) \\ Universidad de Zaragoza, Mariano Esquillor s/n, 50018, Zaragoza, Spain. \\ Tel.+34-976762707, e-mail: analorente@unizar.es \\ ${ }^{2}$ Facultad de medicina y ciencias de la salud, Universitat Internacional de Catalunya \\ ${ }^{3}$ Unidad de investigación en fisioterapia, Universidad de Zaragoza
}

\begin{abstract}
The rotation stress test is used to evaluate stability of the craniocervical junction by assuming that it gives the maximum rotation. However, a more complex manipulation might show a higher rotation: the rotation with extension and contralateral bending. This was tested in vitro with ten upper cervical spine specimens.
\end{abstract}

\section{Introduction}

The mechanical instability of the craniocervical junction can imply from mobility problems of the head and spine to life-altering results due to the near neurovascular structures. Manual mobilizations are used in the clinic to evaluate the quality of the spine stability in patients.

One of the manual mobilizations spread use and well defined in the literature is the rotation stress test [1]. This rotation test consists in rotating the patient's head to the end of its range of motion, allowing also the motion of atlas (C1) but with a lumbrical grip to axis (C2) grasping the lamina with the thumb and index finger of one hand.

The coupled natural movements that occur in the upper cervical spine were studied in vivo by Ishii et al. (2004) [2]. Their study quantified that with left rotation of the head it is also observed right lateral bending and extension, having the same effect with right rotation: left lateral bending (contralateral bending) and extension.

Previous in vitro tests have also shown that to reach the maximum rotation range of motion it is needed a coupled extension movement [3]. However, it is not clear how can be influenced the rotation range of motion by enlarging the extension and lateral bending coupled movements. The goal of this work is studying the difference in rotation between a pure rotation and a rotation with extension and contralateral bending, using manipulations by hand in in vitro testing. And to better understanding this and the stability in head-C2 rotation test, the same two movements were repeated after the transection of the right alar ligament. This was decided because the alar ligaments' main role is the restraint of the head-C2 rotation [4].

\section{Materials and methods}

We examined 10 cryopreserved upper cervical spine specimens; 9 males and 1 female, with a mean age of 74.34 years (range 63-85). The bodies come from the body donor program of the Faculty of Medicine and Health Science from Unversitat Internacional de Catalunya. None of the cadaveric specimens used for this study had evidence of traumatic injuries or surgical scars in head or column. Muscle tissues were carefully removed leaving an osseoligamentous arrangement. The alar ligaments were exposed without damaging its mechanical properties.

The specimens were fixed on a load cell (MC3A, AMTI, USA) at the C2 level, and the skull was manipulated through a metallic handlebar. The rotation was measured using a 3D motion capture system (Vicon, TS series, UK).

\section{Results}

There is not enough evidence about which of the two rotations (pure, $P$, or with larger coupled movements, $C$ ) showed a higher axial rotation. The difference between them was $1.10 \pm 1.89^{\circ}$, considering both sides.

After right alar ligament transection the differences for the right side were $4.04 \pm 4.40^{\circ}$ (P) and $1.24 \pm 4.21^{\circ}$ (C) and for the left side $3.75 \pm 4.04^{\circ}(\mathrm{P})$ and $2.75 \pm 4.07^{\circ}(\mathrm{C})$. 
The variation in the mechanical response between the specimens, for both rotations and before and after alar ligament transection, can be found in Figure 1.

\section{Conclusions}

Rotation with extension and contralateral bending should be also studied in stability tests for the craniocervical junction, as the range of rotation might be higher than in pure rotation for some patients.

A preferable rotation between these two movements to test stability cannot be highlighted in this study due to the anatomical variations presented in our sample size of 10 specimens.

\section{Funding}

From the Instituto Aragones de Fomento, through the agreement with the Impact Laboratory (I3A), where the experimental tests were performed, and

the Gobierno de Aragón (grupo T38_17R), jointly financed with Feder 2014-2020 "Construyendo Europa desde Aragón”.

\section{References}

[1]. OSMOTHERLY, P.G., RIVETT, D., ROWE, L. J. Toward Understanding Normal Craniocervical Rotation Occurring During the Rotation Stress Test for the Alar Ligaments. Physical Therapy. 2013, 93(7), 986-992.

[2]. ISHII, T., MUKAI, Y., HOSONO N., SAKAURA, H., NAKAJIMA, Y., SATO, Y., SUGAMOTO, K. AND YOSHIKAWA, $\mathrm{H}$. Kinematics of the Upper Cervical Spine in Rotation. Spine. 2004, 29(7), E139E144.

[3]. BOSZCZYK, B.M., LITTLEWOOD, A.P., and PUTZ R. A Geometrical Model of Vertical Translation and Alar Ligament Tension in AtlantoAxial Rotation. European Spine Journal. 2012, 21(8), 1575-1579.

[4]. PANJABI, M., DVORAK, J., CRISCO, J.J., ODA, T., WANG, P. AND GROB, D. Effects of Alar Ligament Transection on Upper Cervical Spine Rotation. Journal of Orthopaedic Research. 1991, 9(4), 584-593.
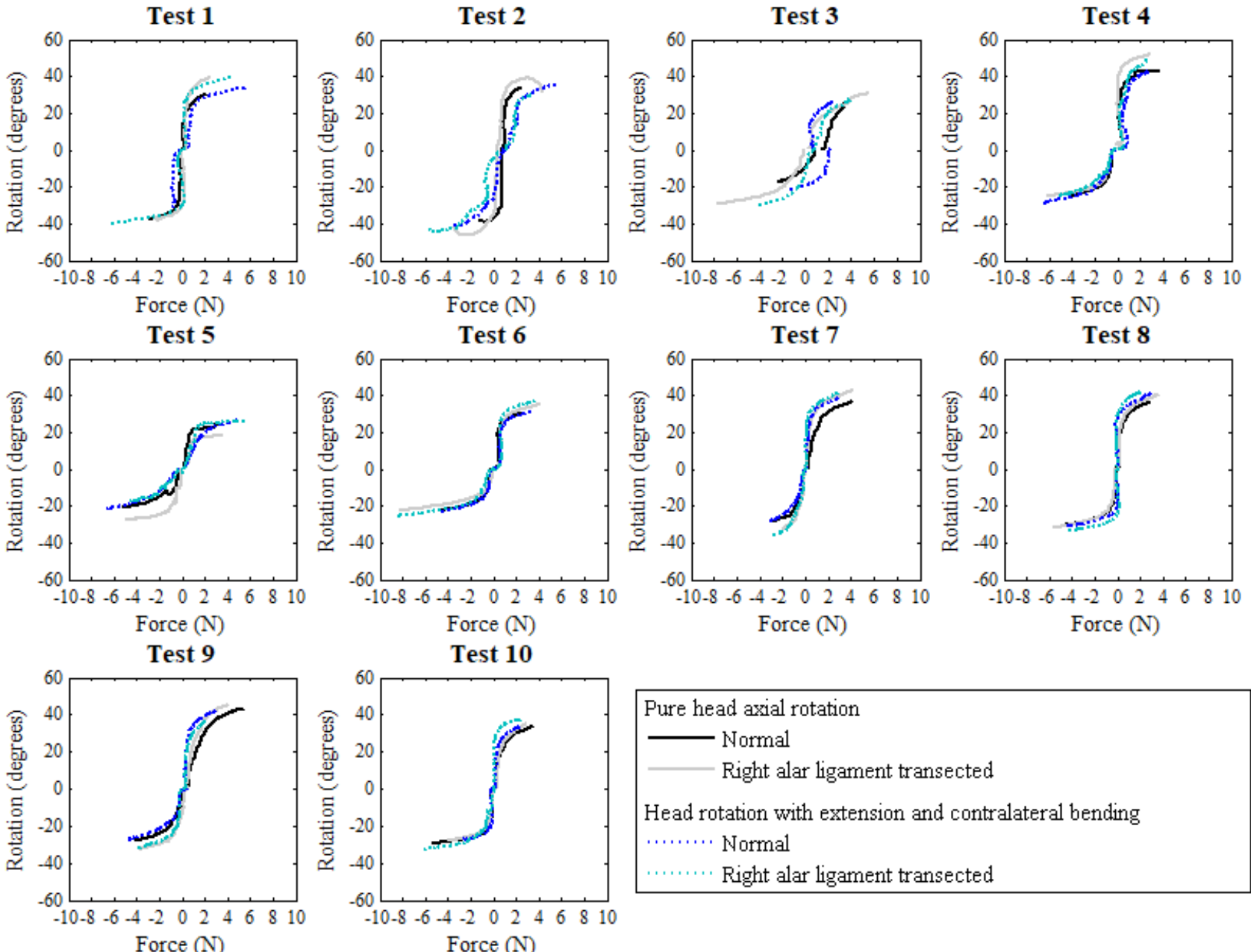

Figure 1 Full range of motion for the rotation head-C2 tracked in each test, depending the applied force in the head. The pure rotation and the rotation with extension and contralateral bending are represented for the normal specimen and for the right alar ligament transection.

Revista “Jornada de Jóvenes Investigadores del I3A”, vol. 7 (Actas de la VIII Jornada de Jóvenes Investigadores del I3A - 6 de junio de 2019). ISSN 2341-4790. 